\title{
The interpretation of dysprosody in patients with Parkinson's disease
}

\author{
J F V Caekebeke, A Jennekens-Schinkel, M E van der Linden, O J S Buruma, R A C Roos
}

\begin{abstract}
Prosodic features in the speech production of 21 patients with idiopathic Parkinson's disease were tested. The appreciation of vocal and facial expression was also examined in the same patients. Significant intergroup differences were found in the prosody production tasks but, in contrast to previous results, not in the receptive tasks on the recognition and appreciation of prosody and of facial expression. The discrepancy between the production and recognition of prosodic features does not support the suggestion that dysprosody in Parkinson's disease is necessarily a disorder of processing emotional information that could be misinterpreted as a dysarthria.
\end{abstract}

This study concerns "dysprosody" and its underlying disorder, in patients with Parkinson's disease (PD). Dysprosody is a wellestablished concomitant of PD, and was thought to result from a hypokinetic dysarthria associated with respiratory, phonatory and articulatory dysfunctions. ${ }^{2-5}$ Recently, however Scott et al reported evidence for a higher, mental origin of speech aberrations in PD patients, and suggested that an abnormality of prosody often gave a false impression of dysarthria. ${ }^{167}$ Two findings were important in interpreting the speech disorder as a failure to process emotional information.

First, a higher mental level of processing was suggested by discovering that dysprosody was not only present in speech production, but that PD patients also failed to appreciate the prosodic features of spoken messages. Second, the failure appeared to exceed the speech modality and to be also present in perceiving or appreciating emotional aspects of visual nonverbal information. The independence from the mode in which emotional information was presented seemed to suggest a supramodal nature of the disorder.

If dysprosody in PD is based on a failure to convey and react to the emotional aspects of information, and not on some type of motor dysfunction, this would have great practical and theoretical relevance. In practical terms, it should act as a guide to the management and treatment of patients. ${ }^{7}$ Theoretically, the issue concerns the functional significance of the basal ganglia. As yet, the controversy over the basal ganglia as either a primarily motor sys$\mathrm{tem}^{8}$ or a system with a role in higher mental functions ${ }^{4}$ has not been resolved. It would even have implications for a revision of current theories on the relation between cerebral dysfunction and disorders of emotion or affect. The right and left cerebral hemispheres have both been suggested as the representational locus of prosody, ${ }^{9}$ with an intrahemispheric distribution of dysprosodia subtypes reflecting the aphasias. ${ }^{10}$

The aims of the study were: (a) to verify dysprosody in a controlled replication study of patients with PD; $(b)$ to explore relations between dysprosody and cognitive, affective and perceptual variables in the same patients.

\section{Subjects and methods}

Subjects

Twenty one PD patients attending the outpatients clinic and 14 control subjects participated after giving informed consent. Clinical information is summarised in table 1 . Exclusion criteria were: (1) age over 75 years; (2) presence of other neurological disease(s); presence of visual and/or auditory defects (screening by clinical methods); (3) presence of metabolic dysfunction (diabetes mellitus, uraemia, liver function disorders). To exclude medication-induced "on-off" variations, antiParkinsonian drugs were withdrawn from the night before the assessment, and all subjects were examined in the morning.

Spouses of the patients were asked to participate as controls to obtain adequate matching for socio-economic status.

\section{Procedures}

Unlike the original study, ${ }^{1}$ we included psychometric measures for formal assessment of cognitive level. The examination of prosody reception and production, and of the

Table 1 Clinical features of Parkinson's disease patients and controls

\begin{tabular}{lll}
\hline & Patients & Controls \\
\hline Number (n) & 21 & 14 \\
Women/Men & $9 / 12$ & $10 / 4$ \\
Age (years) & $62 \cdot 2( \pm 7 \cdot 56)$ & $60 \cdot 9( \pm 9 \cdot 40)^{\star}$ \\
Duration of symptoms (years) & $5 \cdot 5(2-10)$ & \\
Hoehn and Yahr stage II & $\mathrm{n}=4$ & \\
$\quad$ III & $\mathrm{n}=14$ & \\
IV & $\mathrm{n}=3$ & \\
Webster disability score & $10( \pm 6)$ \\
Medication: levodopa + PDI† & $\mathrm{n}=21$ & \\
anticholinergicum & $\mathrm{n}=5$ & \\
bromocriptine & $\mathrm{n}=5$ \\
amantadine & $\mathrm{n}=5$ & \\
beta-blocker & $\mathrm{n}=2$ & \\
antidepressivum & $\mathrm{n}=2$ \\
\hline
\end{tabular}

*no significant difference between patients and controls. †PDI: peripheral decarboxylase inhibitor. 
appreciation of facial expression, replicated the procedures of the original study. Oral responses were tape recorded for later analysis.

\section{COGNITION AND PERCEPTION}

Intelligence (Wechsler Adult Intelligence Scale Revised) ${ }^{11}$ and memory (Wechsler Memory Scale) ${ }^{12}$ were psychometrically determined, according to the test manuals. The individual results were rated by a clinical psychologist who was unaware of whether the protocol was from a PD patient or from a control subject. Cognitive deterioration was judged to be present if a significant discrepancy existed between actual performance and premorbid level, as estimated on the basis of education and occupation.

Word generation (word fluency) assessed the ability to generate words, in one minute periods and as quickly as possible, according to a semantic (animals) or a lexical (words that begin with the letters $U, N, K$ and $A$ ) rule.

The Wisconsin Card Sorting test (Nelson's modification $^{13}$ ), supposedly measuring behavioural flexibility, was also used.

A tone discrimination test ${ }^{14}$ required a yes/ no response to indicate perceived difference between the members of each of 50 pairs of tonal stimuli. The task served to control for non-prosodic defects in pitch perception.

\section{RECOGNITION OF FACIAL EXPRESSION}

The subjects were presented with four cartoons ${ }^{1}$ in succession showing faces that each depicted an emotional state. The subjects were requested $(a)$ to give orally free descriptions of the facial expressions and $(b)$ to respond in yes/ no fashion to seven statements on the emotional qualities of the facial expressions. Together, these tasks helped distinguish between overt and covert appreciative ability.

Elaboration and scoring were guided by the following recent evidence, gathered in extensive research with Dutch speaking normal subjects. The judgement of facial expressions is most likely explained by two fundamental dimensions and six basic emotions. The dimensions are "pleasantness-unpleasantness" and "attention-rejection", supporting Schlosberg's two-dimension theory. ${ }^{15}$ Attention is defined as "open, ready to receive stimuli", and rejection as "closed, as if to shut out stimulation". "Happiness", "sadness", "anger", "disgust", "contempt" and "surprise" are the basic emotions into which perceptions of facial expressions can be categorised, again supporting Woodworth's theory. ${ }^{15}$ Neutral expressions were judged as more "closed" or passive; both the very pleasant and the very unpleasant expressions, as perceived in photographs, appear as more "open" or attentive. In this study, responses were classified according to the two dimensions and six basic categories, with separate groups for neutral and evasive answers.

RECOGNITION OF PROSODY

Subjects were presented with taped statements devoid of emotion. They were requested ( $a$ ) to give orally a same/different judgement of eight pairs of verbally identical but prosodically different statements (discrimination of prosodic differences), (b) to comment upon the vocally expressed moods $(n=8)$, and $(c)$ to comment upon the verbal content of the statement (which was different in two of the eight).

MATCHING OF VISUAL AND VOCAL EXPRESSION

Four cartoons depicting facial expressions of emotion, were also presented in a multiple choice format. Subjects were asked to select the appropriate cartoon for each of four successively presented sentences, that were neutral in content but emotionally different. The sentences were presented by means of a tape recorder.

PRODUCTION OF PROSODY

1) Subjects were requested to distinguish moods by reading seven sentences in angry, hesitating and neutral voices. The recorded responses of the subjects were rated independently by two raters who were unaware of the medical status of the speaker. (a) An overall prosody rating classified the prosodic features of the speech samples as normal or abnormal. (b) Although the components of prosody are interdependent, ${ }^{16}$ volume, pitch, duration pattern (rhythm) and stress of each speech sample were rated on a 4-point scale. The results of the separate ratings, supporting the overall prosody rating, but not adding information and addressing interdependent variables, are not reported.

2) Subjects were asked to tell a story about a picture from the shortened Schuell test. ${ }^{17} \mathrm{~A}$ prosodic abnormality score was determined by rating volume, pitch, intonation, vocal quality, rate, and rhythm as normal (0) or abnormal (1) (modified from Scott and Caird ${ }^{6}$ ).

\section{PRODUCTION OF PROPOSITIONAL SPEECH}

The stories on the Schuell picture were analysed linguistically. In addition to the features scored by Scott and Caird, ${ }^{6}$ two ratios were calculated as indications of "story telling" versus "enumerating" [(nouns + pronouns)/ verbs], and of "linguistic embellishment" [(adjectives + verbs)/nouns]. Deviant utterances were counted as well ( 1 point per deviancy). They were defined according to the reference $^{17}$ given by Scott et al ${ }^{1}$ as (1) speech production less than $\mathbf{4 5}$ words in five minutes, (2) confused and irrelevant utterances, (3) wrong word usage, (4) bad sentence construction, (5) enumeration and (6) unintelligible speech (added by us).

\section{STATISTICAL ANALYSIS}

Group differences between PD patients and control subjects were studied nonparametrically (Mann-Whitney U test). Testing was two-sided, with alpha $=0.05$.

\section{Results}

The groups of PD patients and control subjects, matched for socio-economic status, were comparable for age (table 1). Illness 
Table 2 Cognition and perception of $P D$ patients and controls

\begin{tabular}{|c|c|c|c|}
\hline & $\begin{array}{l}\text { Patients } \\
\text { Mean (SD) }\end{array}$ & $\begin{array}{l}\text { Controls } \\
\text { Mean (SD) }\end{array}$ & $P$ \\
\hline $\begin{array}{l}\text { Intelligence Quotient (IQ) } \\
\text { Full scale IQ } \\
\text { Verbal IQ } \\
\text { Performance IQ } \\
\text { Memory Quotient (MQ) } \\
\text { Cognitive deterioration }\end{array}$ & $\begin{array}{l}104(13 \cdot 1) \\
105(14 \cdot 0) \\
101(13 \cdot 7) \\
109(20 \cdot 2) \\
24 \%(n=5)\end{array}$ & $\begin{array}{l}101(16 \cdot 2) \\
100(17 \cdot 0) \\
105(14 \cdot 5) \\
110(15 \cdot 8) \\
7 \%(n=1)\end{array}$ & $\begin{array}{l}\text { NS } \\
\text { NS } \\
\text { NS } \\
\text { NS } \\
\text { NS }\end{array}$ \\
\hline $\begin{array}{l}\text { Word generation } \\
\text { Semantic } \\
\text { Phonemic } \\
\text { Wisconsin Card Sorting } \\
\text { (total errors) }\end{array}$ & $\begin{array}{r}16(4.1) \\
34(11.5) \\
5(5.9)\end{array}$ & $\begin{array}{r}16(5.4) \\
38(15.9) \\
5(5.5)\end{array}$ & $\begin{array}{l}\text { NS } \\
\text { NS } \\
\text { NS }\end{array}$ \\
\hline $\begin{array}{l}\text { Seashore tone discrimination } \\
\text { (total correct) }\end{array}$ & $33(7 \cdot 6)$ & $33(4 \cdot 7)$ & NS \\
\hline
\end{tabular}

variables in PD patients were not differently distributed in male and female patients.

Psychometric measures of cognition revealed average levels of intelligence and memory in PD and control groups (table 2). However, on the basis of a discrepancy between estimated premorbid cognitive level and present psychometric results on intelligence and memory tests, five patients $(24 \%)$ were judged to function significantly below premorbid cognitive level, as opposed to one control subject $(7 \%)$; the difference was not significant. Word generation and the measure of behavioural flexibility (Wisconsin modified Card Sorting test) did not distinguish PD patients from control subjects (table 2). Pitch discrimination (Seashore test) was not significantly different in the two groups (table 2).

Recognition of visually presented emotional expression did not distinguish PD patients from controls (table 3). The groups did not differ significantly in the appreciation of prosodic features in taped utterances, whether assessed in a voice quality recognition task or in a vocal-visual matching task (table 3 ).

Production of prosody, however, revealed a significant difference between the groups: PD patients were less able to produce the loudness, pitch and rhythm patterns required for expres-

Table 3 Performance in prosodic and linguistic tasks made by $P D$ patients and controls

\begin{tabular}{|c|c|c|}
\hline & $\begin{array}{l}\text { Patients } \\
\text { Mean (SD) }\end{array}$ & $\begin{array}{l}\text { Controls } \\
\text { Mean (SD) }\end{array}$ \\
\hline $\begin{array}{l}\text { Recognition of facial expression: } \\
\text { Description (max 4) } \\
\text { Yes/No responses (max } 28 \text { ) }\end{array}$ & $\begin{array}{r}3.8(0.40) \\
23.8(2.19)\end{array}$ & $\begin{array}{r}3.7(0.47) \\
22.1(4.10)\end{array}$ \\
\hline $\begin{array}{l}\text { Recognition of prosody: } \\
\text { Discrimination (max 8) } \\
\text { Comment upon (max 8) } \\
\text { Linguistic differences } \\
\text { (Yes/No responses; } \max 2 \text { ) }\end{array}$ & $\begin{array}{l}7.7(0.58) \\
7.1(1.09) \\
1.6(0.59)\end{array}$ & $\begin{array}{l}7.8(0.58) \\
7.0(1.41) \\
1.7(0.61)\end{array}$ \\
\hline $\begin{array}{l}\text { Matching of facial and vocal } \\
\text { expression: }(\max 4) \\
\text { Production of prosody: }\end{array}$ & $2.7(1.43)$ & $2 \cdot 6(1 \cdot 15)$ \\
\hline $\begin{array}{l}\text { Angry (max } 7) \\
\text { Hesitating }(\max 7) \\
\text { Neutral }(\max 7) \\
\text { Prosody in picture description } \ddagger\end{array}$ & $\begin{array}{l}3.8(2.11) \\
1.9(1.77) \\
6.8(0.54) \\
2 \cdot 1(1.83)\end{array}$ & $\begin{array}{l}5.1(1.96) \star \\
3.1(2.51) \\
6.9(0.27) \\
0.4(0.76) \dagger\end{array}$ \\
\hline $\begin{array}{l}\text { Production of propositional } \\
\text { speech (linguistic analysis } \\
\text { of picture description) }\end{array}$ & & \\
\hline $\begin{array}{l}\text { Verbs } \\
\text { (Nouns + pronouns)/verbs } \\
\text { (Adjectives + verbs)/nouns } \\
\text { Number of words } \\
\text { Number of utterances } \\
\text { Deviant utterances }\end{array}$ & $\begin{array}{c}13 \cdot 1(7 \cdot 27) \\
1.8(0.64) \\
1.4(0.42) \\
63.9(32 \cdot 48) \\
4.3(2 \cdot 12) \\
1\end{array}$ & $\begin{array}{r}15.4(8.01) \\
1.5(0.54) \\
1.6(0.66) \\
75.3(42.33) \\
5.6(2.92) \\
0.7\end{array}$ \\
\hline
\end{tabular}

sing anger. The prosody components producing neutral statements, however, appeared not to be significantly weaker than in controls. Hesitation was expressed with difficulty in both groups. The prosodic abnormality score for the story telling task revealed significant differences between patients and control subjects.

Propositional speech variables derived from picture description revealed no significant intergroup differences.

\section{Discussion}

This study was mainly concerned with the verification and the interpretation of dysprosody in PD patients. A replication paradigm was chosen, and in addition cognition was formally measured. In agreement with the original study, ${ }^{1}$ our results indicate that there is a difficulty in adapting vocal loudness, pitch and duration to the mediation of mood in PD patients. In particular, the voice modulations required for expressing anger were difficult, presumably because anger is mainly shown by increasing the volume of sound. Our group of PD patients, in contrast with those in the original study, were able to appreciate emotion when it was visually or vocally presented. This finding disagrees with the suggestion of a more general disorder in the processing of emotion as a feature of PD.

The following issues are relevant when trying to explain the difference in the findings between the original ${ }^{1}$ and our replication study: Illness duration and age There is an important difference in illness duration between the two studies; $38 \%$ of the patients in this study had a disease duration of more than six years and none more than 11 years. This compared with $60 \%$ and $25 \%$ respectively in the group studied by Scott et al. ${ }^{1}$ Our patients were slightly younger than those taking part in their study. The significance of illness duration to explain the difference in prosody scores remains unclear. Scott et $a l^{1}$ found no relationship between prosody scores and duration of disease.

Patient selection In the study by Scott et al, ${ }^{1}$ PD patients were selected for having a clinically diagnosed "Parkinsonian speech disorder", a selection criterion not maintained in our study because it was thought unfair to select on the basis of speech disorder if statements on prosody were to hold for PD generally. The PD patients from this study showed impaired production together with unimpaired recognition of prosody, a discrepancy that cannot be explained on the basis of the reported difference in patient selection between the two studies.

Medication The role of the dopaminergic deficit in PD-associated deficits in mental dysfunction is still unclear ${ }^{18}$; the withdrawal of anti-Parkinsonian drugs in this study can hardly be expected to have had a positive effect on the speech disorder.

Level of cognition Cognitive integrity may be of relevance. Although Scott et al deny a difference in cognitive level between their PD 
and control subjects, there is circumstantial evidence of cognitive deterioration in their patient group. First, $46 \%$ of their PD patients could not execute the colour-form sorting task, because of undue concreteness or loss of abstraction in thinking. From their data (recalculating an unpaired $t$ test from table $4^{1}$ ), we might assume that the patients who were unable to perform the sorting task, not only performed significantly worse than the other patients in discrimination of affective and grammatical functions of prosody, but also had significantly worse prosodic abnormality scores. A further indication of cognitive decline of the patients in the original study may be found in the large proportion of linguistically deviant utterances.

The question could be asked whether the patients of this study are representative of the PD population. The Hoehn and Yahr and Webster ratings classify the physical state of the present group as representative of the PD outpatient population. In the present study, cognition was formally measured and mean IQ was found to be within the normal range. However, individual judgements of cognitive decline, made with reference to the personal history of the subjects, indicated mild cognitive deterioration in a lesser percentage $(24 \%)$ than we supposed was present in the original study, but a percentage that agrees with published data on mental decline in idiopathic PD outpatients. ${ }^{19}$ It is quite probable that cognitive integrity is a major determinant of the difference between the original and the replication study. Of course, the possibility remains that PD patients with cognitive deterioration display receptive and expressive dysprosody on the basis of a failure to process emotional information. By replicating and extending the procedures of the original study, we conclude that a failure to process emotional information is not a necessary feature of PD.

There are further reasons for caution in interpreting vocal changes as signs of emotion. Dysprosody is a multifaceted concept. The position of an emotional disorder in PD would have been strong, if a clear dissociation would have been found between adequate linguistical and deficient emotional processing, not only in production (expression) but also in reception (comprehension). Scott et al suggested better linguistic than emotional prosody processing, but the two dimensions were compromised in most of the receptive tasks and their evaluation. A more fundamental question is whether the tasks that are described in this and similar studies are suitable for examining emotion and affect. The subjects are requested to judge, or produce, poses of emotions, which may prompt a predominantly intellectual or propositional attitude.

In concurrence with the present results, Darkins et $a l,{ }^{20}$ when studying comprehension and production of prosody, found only a prosody production deficit in PD, which appeared to be due to a faulty speech production mechanism and not to a loss of the knowledge required to make prosodic distinctions.

In conclusion, we found that (1) the use of loudness, pitch and duration in speech production is impaired in PD, rendering speech prosody abnormal; (2) the origin of the impairment is not necessarily related to an encoding/ decoding disorder of affective behaviour. These findings support the theory of a "hypokinetic dysarthria".?

We are grateful to E A Van Der Velde, biostatistician, for supervising statistical analysis and to $K$ Van Elst for technical
assistance. M P R van den Broecke, phonetician of the State University Utrecht, gave advice on prosody rating.

1 Scott S, Caird FI, Williams BO. Evidence for an apparent sensory speech disorder in Parkinson's disease. $J$ Neurol sensory speech disorder in Parkinson's

2 Darley FL, Aronson AE, Brown JR. Motor speech disorder. Saunders, Philadelphia/London: Saunders, 1975.

3 Mlcoch AG. Diagnosis and treatment of Parkinsonian dysarthria. In: Koller WC, eds. Handbook of Parkinson's disease. New York: Dekker 1987:181-207.

4 Critchley EMR. Speech disorders of Parkinsonism: a review. J Neurol Neurosurg Psychiatry 1981;44:751-8.

5 Kent RD, Rosenbek JC. Prosodic disturbance and neurologic lesion. Brain Language 1982;15:259-91.

6 Scott S, Caird FI. Speech therapy for Parkinson's disease. $J$ Neurol Neurosurg Psychiatry 1983;46:140-4.

7 Scott S, Caird FI. The response of the apparent receptive speech disorder of Parkinson's disease to speech therapy. $J$ Neurol Neurosurg Psychiatry 1984;47:302-4.

8 Marsden CD. The mysterious motor function of the basal ganglia. Neurology 1982;32:514-39.

9 Heilman KM, Bowers D, Speedie L, Coslett HB. Comprehension of affective and non-affective prosody. Neurology 1984;34:917-21.

10 Gorelick PB, Ross ED. The aprosodias: further functionalanatomical evidence for the organisation of affective language in the right hemisphere. $J$ Neurol Neurosurg Psychiatry 1987;50:553-60.

11 Wechsler D. Manual for the Wechsler Adult Intelligence Scale. New York: The Psychological Corporation 1955.

12 Wechsler D, Stone CP. Wechsler Memory Scale (manual). New York: The Psychological Corporation 1945.

13 Nelson HE. A modified card sorting test sensitive to frontal lobe defects. Cortex 1976;12:313-24.

14 Seashore CE, Lewis D, Saetveit JG. Seashore measures of musical talents (manual). New York: The Psychological Corporation 1960.

15 Vlaander GPJ. Structuur in de waargenomen gelaatsuitdrukkingen van emotie (Thesis). Eindhoven: Eindhoven Druk BV/Offset, 1985 .

16 Van Bezooyen $\mathrm{R}$. Characteristics and recognizability of vocal expressions of emotions. Dordrecht: Foris publications, 1984

17 Schuell HS. Minnesota test for differential diagnosis of aphasia. Minneapolis: Univ Minneapolis Press, 1965

18 Bonnet AM, Loria Y, Saint-Hilaire MH, Lhermitte F, Agid $\mathrm{Y}$. Does long-term aggravation of Parkinson's disease result from nondopaminergic lesions? Neurology 1987;37:1539-42

19 Brown RG, Marsden CD. How common is dementia in Parkinson's disease? Lancet 1984;ii:1262-5.

20 Darkins AW, Fromkin VA, Benson DF. A characterization of the prosodic loss in Parkinson's disease. Brain Language 1988;34:315-27. 